\title{
PRODUKTIFITAS DAN PENDAPATAN PETANI SWADAYA, PLASMA, DAN PERUSAHAAN BESAR SWASTA (STUDI KASUS DI PROPINSI KALIMANTAN TIMUR)
}

\author{
(Productivity and Income between Independent Smallholders, Plasma, \\ and Large Private Companies) \\ (Case Study In East Kalimantan Province)
}

\author{
Zulkarnain $^{1}$, M. Erwan Suriaatmaja ${ }^{1}$, dan Abdul Rahmi \\ ${ }^{1}$ Fakultas Pertanian Universitas Mulawarman \\ ${ }^{2}$ Fakultas Pertanian Universitas 17 Agustus 1945 Samarinda \\ Penulis Koresponden : rahmi_untag@yahoo.co.id
}

Article Submitted : 27-07-2021

Article Accepted :01-09-2021

\begin{abstract}
The development of oil palm plantations in East Kalimantan can encourage the improvement of the regional economy and the people's economy. The interest of farmers to cultivate oil palm plantations is quite large, however, the production results are not in line with expectations. The purpose of this study is to determine the differences in productivity and income between independent smallholders, plasma, and large private companies. This research is a qualitative descriptive study referring to quantitative and comparative studies. It was conducted in 5 districts namely, Kutai Kartanegara, Kutai Timur, Penajam Paser Utara, Paser, and Berau in the largest oil palm plantation area in East Kalimantan. The results showed that (1) the productivity of oil palm plantations on large private- and plasma- plantations continued to increase until the age of more than 10 years, while in smallholder self-help plantations the highest productivity was at the age of 9 years, after that there was a decrease in productivity; and (2) the income of large private plantations and plasma plantations continues to increase until the age of the plant is $>10$ years, while in smallholder plantations the highest income occurs at the age of 9 years.
\end{abstract}

Keywords: Productivity, Income, Independent Smallholders, Plasma, and Large Private Companies

\section{PENDAHULUAN}

Tanaman kelapa sawit memiliki arti penting bagi pembangunan perkebunan nasional karena dapat mewujudkan cita-cita bangsa yakni terciptanya masyarakat yang sejahtera. Hasil komoditas kelapa sawit baik berupa bahan mentah maupun hasil olahannya merupakan penyumbang devisa non migas terbesar setelah karet dan kopi. Prospek pasar bagi olahan kelapa sawit cukup menjanjikan, karena permintaan dari tahun ke tahun meningkat baik di dalam maupun di luar negeri. Sebagai negara tropis yang memiliki areal perkebunan yang potensial, Indonesia berpeluang besar untuk mengembangkan perkebunan kelapa sawit. Pengembangan perkebunan kelapa sawit diharapkan dapat memberikan kontribusi positif terhadap pengembangan perekonomian melalui investasi padat modal, terciptanya lapangan dan kesempatan kerja serta terbukanya peluang berusaha.

Minyak sawit adalah bahan baku yang penting untuk bahan makanan ataupun 
industri non pangan, yang memiliki peranan penting dalam rangka memberikan sumbangan peningkatan perekonomian bagi negara dan yang paling penting untuk pemenuhan pangan bagi masyarakat dunia.

Pembangunan perkebunan kelapa sawit dan pabrik pengolahan minyak sawit memberikan banyak hal bagi perkembangan perekonomian melalui peningkatan ekspor hasil komoditi non migas, membuka dan memperluas lapangan kerja, meningkatkan perekonomian daerah serta pengembangan sektor pertanian sub sektor perkebunan.

Luas perkebunan kelapa sawit di Provinsi Kalimantan Timur pada tahun 2019 mencapai 1.228.138 Ha, yang pusat persebarannya yaitu di Kabupaten (Paser, Kutai Timur dan Kutai Kertanegara serta wilayah lainya). Dari luasan tersebut 255,919 Ha sebagai tanaman plasma / rakyat, $14.402 \mathrm{Ha}$ milik BUMN sebagai inti dan 957.817 Ha milik Perkebunan Besar Swasta. Produksi dan produktivitas dengan pola perkebunan rakyat yaitu berturut-turut 2.289.682 ton dan $14.419 \mathrm{~kg} / \mathrm{Ha}$, sedangkan pada pola perkebunan besar swasta yaitu berturut-turut $15.883 .128 \mathrm{Ha}$ dan 22.340 $\mathrm{kg} / \mathrm{Ha}$ (Disbun, 2020). Menurut Ditjen Perkebunan Kementerian Pertanian (2019) bahwa produktivitas perkebunan sawit rakyat hanya 2 ton/ha/tahun, jauh dibandingkan dengan perkebunan besar swasta yang berkisar 4-8 ton/ha/tahun. Berdasarkan data tersebut terjadi perbedaan yang cukup signifikan produksi dan produktivitas kelapa sawit antara pola perkebunan rakyat dan pola perkebunan besar swasta, hal ini juga berpengaruh terhadap pendapatan petani. Permasalahan utama yang dihadapi pada perkebunan rakyat yaitu rendahnya produktivitas tanaman yang disebabkan praktik pengelolaan yang kurang baik.

Tujuan penelitian adalah untuk mengetahui produktivitas dan pendapatan antara petani swadaya, plasma dan perusahaan besar swasta kelapa sawit di Kalimantan Timur.

\section{METODE PENELITIAN}

\section{Metode Penentuan Lokasi}

Lokasi penelitian di 5 kabupaten yaitu: Kutai Kartanegara, Kutai Timur, Penajam Paser Utara, Paser dan Berau yang merupakan wilayah pengembangan kelapa sawit di Kalimantan Timur. Luas areal perkebunan kelapa sawit daerah yang menjadi lokasi penelitian disajikan pada Tabel 1.

Tabel 1. Rekapitulasi Luas Areal Perkebunan Kelapa Sawit Menurut Kabupaten

\begin{tabular}{clc}
\hline No & \multicolumn{1}{c}{ Kabupaten } & $\begin{array}{c}\text { Luasan Total } \\
(\mathrm{Ha})\end{array}$ \\
\hline 1 & Kutai Kartanegara & 204.373 \\
2 & Kutai Timur & 357.059 \\
3 & Penajam Paser Utara & 32.278 \\
4 & P a s e r & 86.724 \\
5 & B e r a u & 115.845 \\
\hline \multicolumn{2}{c}{ Total } & 796.279 \\
\hline
\end{tabular}

Sumber: Dinas Perkebunan Provinsi Kalimantan Timur 2020

\section{Jenis dan Sumber Data}

Jenis data yang dikumpulkan adalah : data sekunder diperoleh melalui penelusuran pada beberapa instansi terkait.

(1) data primer diperoleh dinas terkait; (2) 


\section{Pengumpulan Data}

Menurut Usman dan Akbar (2003) bahwa teknik pengumpulan data dapat dilakukan melalui wawancara, observasi, angket dan dokumentasi. Dalam penelitian ini dilakukan dengan metode wawancara, observasi lapangan dan studi literatur.

\section{Analisis Data}

\begin{tabular}{lrr}
\multicolumn{1}{c}{ Data hasil } & penelitian & $\begin{array}{r}\text { yang } \\
\text { dikumpulkan dianalisis }\end{array}$ \\
dengan & metode \\
deksriptif kuantitatif. & Menurut & Sugiono \\
(2008) bahwa penelitian deskriptif & dilakukan \\
untuk mendiskripsikan suatu & gejala,
\end{tabular}

peristiwa, dan kejadian yang terjadi secara faktual, sistematis, dan akurat.

\section{HASIL DAN PEMBAHASAN}

\section{Produktivitas}

Salah satu tujuan pengelolaan kebun kelapa sawit adalah untuk memperoleh produktivitas tanaman yang tinggi yaitu produksi yang dapat dicapai sesuai dengan kelas kesesuaian lahan. Produktivitas tanaman kelapa sawit di Kalimantan disajikan pada Tabel 2.

Tabel 2. Produktivitas Tanaman Kelapa Sawit di Kalimantan Timur

\begin{tabular}{rcrrr}
\hline & Umur & \multicolumn{2}{c}{ Produktivitas } & (ton/ha/tahun) \\
\cline { 3 - 5 } No. & $\begin{array}{c}\text { Tanaman } \\
(\text { Tahun })\end{array}$ & $\begin{array}{c}\text { Perkebunan } \\
\text { Besar }\end{array}$ & Plasma & Swadaya \\
\hline 1 & 3 & $7,326.42$ & $6,134.74$ & $5,368.04$ \\
2 & 4 & $13,546.98$ & $11,896.42$ & $11,567.82$ \\
3 & 5 & $16,352.03$ & $13,654.23$ & $12,764.43$ \\
4 & 6 & $19,213.21$ & $17,657.07$ & $14,432.72$ \\
5 & 7 & $22,985.01$ & $21,653.65$ & $17,263.46$ \\
6 & 8 & $25,354.34$ & $24,873.05$ & $20,564.82$ \\
7 & 9 & $26,213.54$ & $25,863.62$ & $21,765.65$ \\
8 & $>10$ & $28,546.96$ & $26,648.50$ & $20,273.50$ \\
\hline
\end{tabular}

Sumber: Data Primer Diolah, 2019

Berdasarkan data yang disajikan pada Tabel 2 di atas menunjukkan bahwa produktivitas tanaman kelapa sawit pada perkebunan besar dan plasma terus meningkat sampai umur lebih dari 10 tahun, sedangkan pada perkebunan swadaya rakyat produktivitas tertinggi pada umur 9 tahun, setelah itu terjadi penurunan produktivitas. Keadaan ini juga sesuai dengan hasil penelitian yang dilaporkan oleh Tety (2013) bahwa produktivitas kebun kelapa sawit pola swadaya adalah lebih rendah dibandingkan dengan produktivitas kebun plasma maupun perkebunan besar.

Berdasarkan hasil wawancara dengan responden bahwa penyebab rendahnya produktivitas perkebunan rakyat adalah input pertanian yang diberikan belum maksimal yang meliputi : (1) pembibitan, (2) pemeliharaan / perawatan tanaman, dan (3) pemanenan.

1. Pembibitan

Sebagian besar pekebun rakyat di Kalimantan Timur memperoleh bibit dengan cara membeli melalui perantara tanpa memperhatikan legalitas benih dan tanpa pemeriksaan oleh balai benih, sedangkan sebagian kecil pekebun memperoleh bibit yang dibagikan oleh Dinas Perkebunan. Terdapat sekitar $20 \%$ responden yang membeli bibit siap tanam dari penangkarpenangkar benih lokal yang belum diketahui legalitasnya. Pelaksanaan kegiatan pembibitan juga masih belum dilaksanakan dengan baik sehingga berpengaruh terhadap kualitas bibit yang ditanam. Hal ini sangat berbeda dengan yang dilakukan oleh perkebunan besar, dimana setiap tahan 
pembibitan mulai dari pemilihan varietas, pre nursery sampai dengan main nursery telah direncanakan karena proses pembibitan membutuhkan biaya dan tenaga kerja yang besar dan sangat berpengaruh terhadap produktvitas tanaman. Sesuai dengan pendapat Lembaga Sertifikasi bahwa rendahnya produktivitas kebun rakyat adalah akibat petani ingin menanam sawit dengan cepat dan murah, tanpa mempedulikan lagi hasilnya. Padahal, salah memilih bibit, kerugian akan ditanggung untuk waktu yang lama (www.sertifikasimisb diakses 2 Juni 2020).

2. Pemeliharaan

Tanaman kelapa sawit membutuhkan pemeliharaan agar dapat tumbuh dan berproduksi secara baik. Kegiatan pemeliharaan tanaman menghasilkan meliputi penunasan, perawatan gawangan, pemeliharaan piringan, pemupukan dan pengendalian OPT. Pekebun rakyat hanya melaksanakan beberapa kegiatan pemeliharaan tanaman, utamanya adalah pemupukan, perawatan piringan dan penunasan sedangkan perawatan gawangan dan pengendalian OPT dianggap tidak terlalu penting dalam kegiatan budidaya kelapa sawit sehingga hanya sebagian kecil responden yang melaksanakan kegiatan tersebut. Kegiatan penunasan dilakukan bersamaan dengan pemanenan, begitu juga dengan perawatan piringan dilaksanakan bersamaan dengan pemupukan.

Pemupukan yang tepat belum sepenuhnya diterapkan khususnya untuk dosis dan waktu pemupukan karena terkendala biaya, ketersediaan stok pupuk, dan pengetahuan responden tentang cara pemupukan yang tepat masih tergolong rendah, padahal pemupukan adalah cara menggantikan unsur hara di dalam tanah yang diambil oleh tanaman agar dapat menjaga produktivitas dan biaya pemupukan mengambil $50 \%$ dari biaya produksi sehingga dengan melakukan efisiensi pemupukan dapat mengurangi biaya produksi. Hanya $30 \%$ responden yang telah memupuk tepat dosis dan tepat waktu (2 kali setahun). Penentuan dosis pupuk hanya didasarkan pada pengalaman atau informasi dari Petugas Penyuluh Lapangan, namun belum didasarkan pada hasil analisis tanah dan jaringan tanaman. Pekebun tidak memiliki pengetahuan untuk melakukan metode dan pengaplikasiannya dalam pemupukan kelapa sawit. Seperti dinyatakan oleh Syahputra dan Santosa (2016) bahwa faktor-faktor penyebab rendahnya mutu TBS pekebun rakyat adalah benih yang tidak bersertifikasi, proses pembibitan yang tidak sesuai standar, dan pemberian pupuk tidak sesuai rekomendasi.

3. Pemanenan

Aspek penting dari pemanenan kelapa sawit adalah tingkat kematangan buah yang tepat, yaitu saat brondol 5. Terdapat $80 \%$ responden melakukan panen setiap 3 bulan sekali atau 4 kali dalam setahun dan dapat berkurang menjadi 3 kali jika buah tidak terlampau banyak. Berdasarkan hasil wawancara dengan beberapa petani terdapat kecenderungan bahwa petani dapat mengurangi periode panen menjadi lebih lama jika harga TBS relatif rendah untuk menekan biaya pemanenan sehingga kualitas buah yang dipanen menjadi rendah.

\section{Pendapatan}

Pendapatan pekebun kelapa sawit pada perkebunan besar, plasma dan swadaya disajikan pada Tabel 3. 
Tabel 3. Pendapatan Pekebun Kelapa Sawit Kalimantan Timur

\begin{tabular}{|c|c|c|c|c|}
\hline \multirow[b]{2}{*}{ No. } & \multirow{2}{*}{$\begin{array}{c}\text { Umur } \\
\text { Tanaman } \\
\text { (Tahun) }\end{array}$} & \multicolumn{3}{|c|}{ Pendapatan (Rp/ha/tahun) } \\
\hline & & $\begin{array}{c}\text { Perkebunan } \\
\text { Besar }\end{array}$ & Plasma & Swadaya \\
\hline 1 & 3 & $6,593,778.00$ & $1,840,422.00$ & $3,757,628.00$ \\
\hline 2 & 4 & $12,598,691.40$ & $3,866,336.50$ & $8,097,474.00$ \\
\hline 3 & 5 & $15,534,428.50$ & $5,120,336.25$ & $8,935,101.00$ \\
\hline 4 & 6 & $18,828,945.80$ & $6,709,686.60$ & $10,247,231.20$ \\
\hline 5 & 7 & $22,885,025.21$ & $8,661,460.00$ & $12,429,691.20$ \\
\hline 6 & 8 & $28,270,089.10$ & $10,446,681.00$ & $14,806,670.40$ \\
\hline 7 & 9 & $29,437,805.42$ & $11,638,629.00$ & $16,324,237.50$ \\
\hline 8 & $>10$ & $32,829,008.93$ & $21,318,800.00$ & $15,306,492.50$ \\
\hline
\end{tabular}

Sumber: Data Primer Diolah, 2019

Pada Tabel 3 menunjukkan bahwa pendapatan pekebun kelapa sawit swadaya di Kalimantan Timur memperoleh pendapatan rata-rata tertinggi pada umur tanaman 9 tahun yaitu sebesar Rp. 16.324.237,50/hektar/tahun sedangkan untuk umur tanaman lebih dari 10 tahun rata-rata pendapatan pekebun swadaya mengalami penurunan, dari $60 \%$ responden umur tanaman sudah mencapai umur di atas 20 tahun sehingga tingginya biaya produksi dan penurunan produktivitas yang mengakibatkan terjadi penurunan pendapatan. Untuk pendapatan perkebunan besar dan perkebunan plasma terus meningkat sampai tanaman berumur lebih dari 10 tahun. Pendapatan perkebunan besar swasta pada umur > 10 tahun mencapai Rp 32.829.008,93,- dan pada perkebunan plasma adalah sebesar 21.318.800,00,-. Namun demikian untuk perkebunan plasma rata-rata pendapatan pada tahun 3 sampai tahun ke 9 dibebani oleh potongan kredit bank, bagi hasil koperasi dan perusahaan inti sesuai dengan kesepakatan yang berlaku pada tiap wilayah penelitian. Hasil penelitian ini serupa dengan hasil penelitian yang dilaporkan oleh Lifianthi, dkk (2018) bahwa pendapatan petani kelapa sawit pola plasma adalah lebih tinggi dibandingkan dengan pendapatan petani kelapa sawit pola swadaya (rakyat).

\section{KESIMPULAN DAN SARAN}

\section{Kesimpulan}

1. Produktivitas tanaman kelapa sawit pada perkebunan besar dan plasma terus meningkat sampai umur lebih dari 10 tahun, sedangkan pada perkebunan swadaya rakyat produktivitas tertinggi pada umur 9 tahun, setelah itu terjadi penurunan produktivitas.

2. Pendapatan perkebunan besar swasta dan perkebunan plasma terus meningkat sampai umur tanaman > 10 tahun, sedangkan pada perkebunan rakyat pendapatan tertinggi terjadi pada umur umur 9 tahun.

\section{Saran}

1. Perlu adanya kemitraan yang baik antara pekebun rakyat dan perkebunan besar swasta.

2. Perlu dilakukan pengawasan, penyuluhan dan peningkatan program oleh Pemerintah dalam rangka untuk meningkatkan produktivitas dan pendapatan perkebunan rakyat.

\section{DAFTAR PUSTAKA}

Dinas Perkebunan Provinsi Kalimantan Timur. 2020. Laporan Tahunan Dinas Perkebunan Provinsi Kalimantan Timur, Samarinda. 
Kadir, H. Dan Syapsan. 2012. Peranan Perkebunan Kelapa Sawit dalam Menyerap Tenaga Kerja di Kabupaten Rokan Hulu. Jurnal Sosial Ekonomi Pembangunan. Tahun III. No. 7. November 2012. Hal 24 - 32.

Lifianthi, S.Oktarina dan E. Rosana. 2018. Analisis Produktivitas dan Pendapatan Kelap Sawit Petani Plasma dan Swadaya Di Sumatera Selatan. Jurusan Sosek Faperta Unsri, Palembang.

Sugiono. 2008. Metodologi Penelitian Kuantitatif, Kualitatif. Alfabeta, Bandung.

Syahputra, D.A. dan T.N.B. Santosa. 2016. Identifikasi Faktor-Faktor Rendahnya Mutu TBS Di Perkebunan Rakyat. Jurnal Agromast Volume 1 (2) : 1-16.
Syahza, Almasdi. 2011. Percepatan Ekonomi Pedesaan Melalui Pembangunan Perkebunan Kelapa Sawit. Jurnal Ekonomi Pembangunan. Volume 12, Nomor 2, Desember 2011, hal 297-310.

Tety, E. 2013. Analisis Pemasara dan Transmisi Harga TBS Kelapa Sawit pada Petani Swadaya Di Desa Sari Galuh Kecamatan Tapun Kabupaten Kampar. Faperta Universitas Riau, Riau.

Usman, H. Dan R.P.S. Akbar. 2003. Pengantar Statistika. Bumi Aksara, Jakarta.

www.sertifikasimisb.com/berita/item/69penyebab-rendahnya-produktivitassawit-petani.html diakses, 2 Juni 2020. 